\title{
Parto no Brasil: intervenção médica ou protagonismo da mulher?
}

O parto é um evento historicamente natural que finaliza a gestação, transformando a mulher em mãe. A mudança de parto domiciliar para parto hospitalar, no Brasil, ocorreu no século XX, com a crescente evolução da assistência hospitalar, seguindo a tendência dos países desenvolvidos. Este artigo tem o objetivo de delinear a evolução histórica no Brasil da assistência à mulher no parto, a partir do século XIX e os principais tipos de parto protagonizados na atualidade. Foi realizada uma pesquisa bibliográfica exploratória, através de documentos governamentais, livros e periódicos em sites oficiais do governo brasileiro e bases de dados eletrônicos como Google Acadêmico, LILACS e SciELO. As palavras-chave utilizadas foram: parto normal; parto humanizado; cesárea; e parteira, entre janeiro e abril de 2018. À seleção dos textos elegíveis e a avaliação de sua qualidade metodológica foi realizada independentemente por quatro revisores, sendo excluídos artigos que fugiam da temática proposta ou apresentassem data inferior ao ano de 2003. A partir deste estudo, foi possível identificar os principais tipos de parto e a evolução do nascimento contemplando, a problemática do processo de hospitalização do parto e as tentativas dos movimentos sociais e ações de políticas públicas, no intuito de frear este processo e redimensionar à assistência ao parto na ótica da humanização. Para que a mulher retomasse o empoderamento da sua vontade, e se deter no direito de escolher o tipo de parto que desejar para garantir uma experiência ímpar e intransferível na história da sua maternidade e para garantir este protagonismo da mulher no parto, é necessário que a equipe multiprofissional esteja preparada para adotar as boas práticas, diminuir a intervenção na assistência ao parto e coíba atos de violência à mulher.

Palavras-chave: Parto Normal; Parto Humanizado; Cesárea; Parteira.

\section{Childbirth in Brazil: medical intervention or protagonism of the woman?}

\begin{abstract}
Childbirth is a historically natural event that ends gestation, turning the woman into a mother. The change from home delivery to hospital delivery in Brazil occurred in the 20th century, with the increasing evolution of hospital care, following the trend of developed countries. This article aims to delineate the historical evolution in Brazil of the care of women in childbirth, beginning in the nineteenth century and the main types of childbirth that currently play a role. An exploratory bibliographical research was carried out through government documents, books and periodicals on official Brazilian government websites and electronic databases such as Google Academic, LILACS and SciELO. The used keywords were: normal delivery; humanized birth; cesarean section; and midwife between January and April 2018. The selection of the eligible texts and the evaluation of their methodological quality was independently performed by four reviewers, excluding articles that were not covered by the proposed theme or were dated less than the year 2003. Based on this study, it was possible to identify the main types of childbirth and the evolution of the birth contemplating, the problematic of the process of hospitalization of the childbirth and the attempts of the social movements and actions of public policies, in order to restrain this process and to resize to the delivery assistance in the optics of humanization. In order for the woman to regain the will of her will, and to hold the right to choose the type of delivery she wishes to guarantee a unique and untransferable experience in the history of her motherhood and to guarantee this role of the woman in childbirth, multiprofessional team to be prepared to adopt good practices, reduce intervention in childbirth care and prevent violence against women.
\end{abstract}

Keywords: Normal birth; Humanized birth; Cesarean section; Midwife.

\section{Topic: Fisioterapia}

Reviewed anonymously in the process of blind peer.

Gisely do Brasil

Faculdade Jangada, Brasil

http://lattes.cnpq.br/1542135710964446

giselybrasileao@gmail.com

Débora Costa Neves

Faculdade Guaraí, Brasil

http://lattes.cnpq.br/0676858210284423

deboracosta1994@outlook.com

Daniela Maristane Vieira Lopes Maciel id

Faculdade Guaraí, Brasil

http://lattes.cnpq.br/0591590391105455

http://orcid.org/0000-0001-5934-0219

daniela.marciel@iescfag.edu.br

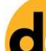

DOI: 10.6008/CBPC2236-9600.2018.002.0002
Received: 03/08/2019

Approved: 18/08/2019

Rogério Carvalho de Figueredo

Faculdade Guaraí, Brasil

http://lattes.cnpq.br/2845056129867931

rogerio.figueredo@iescfag.edu.br

\section{Referencing this:}

BRASIL, G.; NEVES, D. C.; MACIEL, D. M. V. L.; FIGUEREDO, R. C.. Título: subtítulo. Scire Salutis, v.8, n.2, p.9-23, 2018. DOI:

http://doi.org/10.6008/CBPC2236-9600.2018.002.0002 


\section{INTRODUÇÃO}

O parto é o momento que finaliza o período gestacional, e o desfecho do nascimento pode acontecer de duas maneiras: pelo canal de parto através da via vaginal, denominado 'parto normal', ou a remoção por via transabdominal, denominado 'parto cirúrgico' ou 'cesárea' (REIS et al., 2009). A vivência do trabalho de parto é considerada um evento extremamente importante na vida das mulheres, sendo visualizado como um processo deslumbrante, um momento ímpar, onde a mulher passa a ser mãe e responsável por uma nova vida. Portanto, o ciclo gravídico puerperal compreendido pela gestação, o parto e o puerpério, tornam-se uma experiência incomparável e enriquecedora para todos os envolvidos no processo (SANTANA et al., 2015).

Com o passar do tempo, os atos fisiológicos do parto e do nascimento passaram a ser vistos como patológico, o que levou ao aumento de técnicas medicamentosas, levando ao crescimento de procedimentos cirúrgicos, elevando as taxas de cesáreas no Brasil e no mundo. Onde atualmente gira em torno de 55,5\% (SANTA CATARINA, 2017).

O trabalho de parto e parto, antes vivenciados como um momento íntimo, familiar e domiciliar, passaram a ser executados dentro do hospital na presença do médico com práticas intervencionistas que violavam o direito e empoderamento milenar feminino, no que tange à sua maternidade (PONTES et al., 2014), e o acompanhante de escolha da mulher sai de cena, e ela passou a parir apenas na presença da equipe multidisciplinar (VENDÚSCULO et al., 2015).

Culturalmente, o ritual do parto era executado por mulheres, ficando a cargo das parteiras e não sendo considerado um ato médico. Nos casos em que ocorriam complicações ou problemas, os cirurgiõesparteiros eram solicitados a intervirem, mas as intervenções feitas por eles eram tão ineficazes quanto as das parteiras e, normalmente, resumia-se em retirar um feto vivo de sua mãe morta (PONTES et al., 2014).

A mudança de parto domiciliar para parto hospitalar nos países como Estados Unidos, Inglaterra, França, Noruega e Suécia, aconteceu no início do século XX, no período entre guerras; já no Brasil, essa prática somente passou a ser rotineira após a década de 1960, devido à crescente amplificação da assistência hospitalar (LEISTER et al., 2013).

Em função de tantas transformações que foram desenvolvidas para melhor atender a equipe de saúde e a gestante, a parturiente passou de sujeito a objeto, ou seja, uma pessoa que pouco ou nada decide a respeito de como o parto será conduzido. Por isso, há um movimento de humanização do parto, preconizado pelo Ministério da Saúde (MS), solicitando assistência integral e humanizada à mulher, como uma tentativa de empoderamento da mulher neste processo (VENDÚSCULO et al., 2015).

No Brasil, o MS exerce um papel normatizador e regulador, estabelecendo um conjunto de ações, através de portarias ministeriais, com o objetivo de estimular a melhoria da assistência obstétrica. A análise dessas portarias, e em alguns casos de seus impactos iniciais, compõe o cenário da assistência obstétrica atual permitindo sua melhor compreensão. Assessorar às mulheres no momento do parto e nascimento com segurança e dignidade é compromisso fundamental do governo brasileiro (SANTOS et al., 2016). 
O Programa de humanização no pré-natal e nascimento no Brasil determina os princípios da atenção que devem ser oferecidos e estimula estados, municípios e serviços de saúde a cumprirem seu papel, permitindo, a cada mulher, o direito de cidadania, dando à luz e recebendo uma assistência humanizada e de boa qualidade (SANTA CATARINA, 2017). Este artigo tem o objetivo de delinear a evolução histórica no Brasil da assistência à mulher no parto, a partir do século XIX e os principais tipos de parto protagonizados na atualidade.

\section{METODOLOGIA}

O estudo caracteriza-se como revisão bibliográfica exploratória, baseado em documentos governamentais, livros e periódicos publicados entre 2003 e 2018. Para isso, foram consultadas sites oficiais do governo brasileiro e bases de dados on-line como SciELO, LILACS e Google Acadêmico entre janeiro e abril de 2018. Os Descritores em Ciências da Saúde (DCS) utilizados foram: Parto Normal, Parto Humanizado, Cesárea e Parteira. À seleção dos textos elegíveis e a avaliação de sua qualidade metodológica foi realizada independentemente por quatro revisores, sendo excluídos artigos que fugiam a temática proposta ou apresentassem data inferior ao ano de 2003.

\section{DISCUSSÃO TEÓRICA}

\section{Evolução histórica do parto}

No final do século XIX, os partos eram realizados nas residências por parteiras. Ter o bebê fora de casa não era uma prática comum, ocorrendo apenas em situações extremas. 0 médico atendia somente casos complicados, quando a parteira não conseguia resolver o problema. $\mathrm{O}$ acesso à parteira envolvia fatores sociais e emocionais, pois tinha a vantagem de auxiliar nas tarefas domésticas, substituindo e ajudando a mulher por um algum tempo após o parto. Estas eram levadas para dentro do ambiente domiciliar da mulher, realizando o processo de parturição em um meio familiar e aconchegante (LEISTER et al., 2013).

Porém, com a perseguição às parteiras, alegando-se sua desqualificação, ocasionando seu banimento, levaram ao desaparecimento de um conjunto significativo de conhecimentos que as mulheres tinham sobre seus corpos, suas dinâmicas e seus produtos. Aquelas que buscavam o hospital para dar à luz eram, comumente as que não possuíam posição social e procuravam a maternidade em último caso. Até o início do século $\mathrm{XX}$, o hábito de trazer o médico para o atendimento domiciliar do parto permaneceu exclusivo às elites e classes médias urbanas.

Salientando que os primeiros partos hospitalares eram realizados nas enfermarias de alas femininas dos hospitais gerais, visto que ainda não haviam sido instituídas as maternidades. Estas só foram criadas na segunda metade do século XX na Inglaterra, nos Estados Unidos, na França e na Alemanha (PONTES et al., 2014).

Com a chegada do século XX e a institucionalização da assistência e o predomínio do parto hospitalar, o cuidado à mulher e à família sofreu várias modificações. A apropriação do saber médico, nesta área, culminou com o estabelecimento da medicalização do corpo feminino. Com a institucionalização, muito se 
ganhou na questão tecnológica, mas também muito se perdeu em relação ao ambiente acolhedor que ocorria no domicílio (VENDRÚSCULO et al., 2013).

A partir dessas modificações, o aumento de intervenções no ciclo gravídico-puerperal e a excessiva medicalização contribuíram para um novo cenário de parturição, no qual a mulher passou a ser submetida a procedimentos desnecessários, e sua autonomia deixou de ser respeitada. Os profissionais de saúde, consequentemente, passaram a ganhar destaque ao realizar esses procedimentos e tornaram-se os principais protagonistas deste evento (POSSATI et al., 2017).

Um fator que influenciou o aumento da hospitalização do parto no Brasil foi a criação, em 1967, do Instituto Nacional de Previdência Social (INPS). Por intermédio da unificação dos institutos de aposentadorias e pensões no INPS, adjunto à expansão da assistência hospitalar, através do crescimento de empresas de saúde, o sistema trabalhava com três segmentos que eram o privado, a seguridade social para empregados regulares e subvenção do poder público, através do MS e das secretarias estaduais e municipais, que eram as instituições de caridade para os mais pobres (LEISTER et al., 2013).

Até metade da década de 80 , as políticas de saúde voltadas à saúde da mulher eram deficientes, compreendendo apenas sua função de reprodutora e mãe, sem muitas ligações, ao que se referia a outras questões de saúde. Por muito tempo o Brasil prosseguiu imparcial quanto aos direitos sexuais e reprodutivos da mulher. A doutrina vigente para essa população se embasava no Programa Materno-infantil, criado em 1977, este se restringia à prevenção da gestação de alto risco, não tendo em consideração outros aspectos imprescindíveis.

Foi em 1983, com a fundação do Programa de Assistência Integral à Saúde da Mulher (PAISM), que o sistema de saúde passou a abranger um paradigma de assistência baseado nos princípios de equidade e integralidade, os quais englobam as mulheres nas mais diversas áreas e em todos os seus ciclos vitais (PONTES et al., 2014).

Em 1990, o Brasil esteve presente na 23a Conferência Sanitária Pan-Americana e se comprometeu a reduzir a mortalidade materna em 50\% no decorrer da década. Desde agosto de 1993 é aprovada pela portaria n.1.016 as Normas Básicas para Implantação do Sistema de Alojamento Conjunto. Em 1994 na Conferência Internacional sobre População e Desenvolvimento ocorrida no Cairo ratificou o direito à liberdade e aos direitos humanos de exercer a sexualidade, concepção e anticoncepção.

A 4a Conferência Mundial sobre a Mulher em Beijing, em 1995, declarou o direito da mulher de desfrutar o mais elevado nível de saúde. Em 1996, a Organização Mundial de Saúde (OMS) lança recomendações na atenção ao parto normal. Em 1999, a portaria no 985, de 5 de agosto de 1999, cria o Centro de Parto Normal-CPN, no âmbito do SUS, destinado ao atendimento à mulher no período gravídicopuerperal (SANTOS et al., 2016).

No final do século XX, também cresce o movimento da Medicina Baseada em Evidências, que busca basear os cuidados médicos em evidências científicas de eficácia e segurança dos procedimento. Para a OMS, o parto é entendido como um evento natural e o nascimento por via vaginal é considerado o melhor modelo 
quando levado em conta os desfechos de saúde materna e do bebê, sendo a intervenção mínima considerada o paradigma a ser seguido na assistência (ZENARDO et al., 2017).

Em 2000, o Programa de Humanização no Pré-natal e Nascimento (PHPN), estabelecendo limite por hospital, estipulando o percentual máximo de cesarianas em relação ao número total de partos realizados, trazendo com isso novas recomendações de práticas clínicas e abordagens terapêuticas com base em evidências científicas (POSSATI et al., 2017). Nessa ótica de ação integrada à saúde materna e infantil é implantado o método canguru, para entender a atenção humanizada ao recém-nascido de baixo peso (PONTES et al., 2014; SANTOS et al., 2016).

Em 2003, a portaria no 653/GM estabelece que o óbito materno passe a ser notificado para a ocorrer investigação dos fatores determinantes e as possíveis causas destes óbitos, como também para que se adote medidas que possam evitar novos casos de mortes maternas. Em 2004, foi lançado o Pacto Nacional pela Redução da Mortalidade Materna e Neonatal, buscando promover melhoria na atenção obstétrica e neonatal. Também foi instituída a Política Nacional de Atenção Integral à Saúde da Mulher (PNAISM) que reflete o compromisso com a implementação de ações de saúde que assegurem os direitos humanos das mulheres reduzindo a morbimortalidade por causas preveníveis e evitáveis (BRASIL, 2011).

Em 2005, com a criação da Lei no. 11.108 de 7 de abril de 2005, passou a vigorar o direito da parturiente a um acompanhante indicado pela mesma, durante todo o período de trabalho de parto, parto e pós-parto imediato nos serviços de saúde do Sistema Único de Saúde - SUS (BRASIL, 2011). Pela portaria no 2.799 de 18 de Novembro de 2008 é estabelecido no SUS a Rede Amamenta Brasil, a rede é considerada uma estratégia de promoção, proteção e incentivo ao aleitamento materno na rede de atenção básica (PASSANHA et al., 2013). Indo de encontro a necessidade de a amamentação ser compreendida pelos profissionais e pela sociedade como um processo não apenas biológico, mas também social e cultural (BRASIL, 2011).

Em 2011, ocorreu o redesenho na política de saúde da mulher por meio da Portaria no 1.459 de 24 de junho de 2011, na qual o Governo Federal instituiu no âmbito do SUS a Rede Cegonha que estabeleceu diretrizes a serem implementadas na assistência à mulher grávida. Dentre seus objetivos, reafirmou o modelo humanizado de atenção ao parto normal e à criança até os dois anos de idade. Nesse redesenho estrutural e organizacional a ser implantado de forma gradativa em todo o território nacional, prioriza-se regiões incluídas em critério epidemiológico das altas taxas de cesariana, de mortalidade infantil, razão da mortalidade materna e densidade populacional (BRASIL, 2017; ALVES et al., 2017).

O estudo multicêntrico brasileiro, chamado Nascer Brasil, realizado em base hospitalar, composto por 23.940 puérperas e seus recém-nascidos das diferentes regiões do país, constatou que $56,8 \%$ apresentavam risco obstétrico habitual no parto, ou seja, sem condições de saúde que indicassem o uso de procedimentos e intervenção cirúrgica. Dentre essas mulheres, 45,5\% realizaram cesárea e 54,5\% tiveram parto vaginal, porém, apenas 5,6\% tiveram parto normal sem nenhuma intervenção (LEAL et al., 2014). Esse cenário é considerado alarmante quando se leva em conta que a OMS recomenda uma taxa de cesáreas entre 10 a 15\% (ZANARDO et al., 2017). 
A retirada do papel de protagonista torna a mulher frágil e submissa a uma situação que a infantiliza, fragiliza, descaracteriza e violenta. O parto e do nascimento passa a ser encarado com medo devido à ameaça de riscos de dor, de sofrimento e de morte, e a cesariana passa a ser uma possibilidade de fuga e de proteção da dignidade, uma vez que o modelo de parto 'normal' é considerado degradante (SANTA CATARINA, 2017).

Considerando a necessidade de se estabelecerem parâmetros sobre a operação cesariana no Brasil e diretrizes nacionais para a sua utilização e acompanhamento das mulheres a ela submetidas, o governo federal sanciona através da portaria de no 306 de março de 2016, sancionou as diretrizes de atenção à gestante em relação ao parto por cirurgia cesariana, buscando estabelecer parâmetros e instruções nacionais para a sua realização e acompanhamento das mulheres submetidas ao procedimento (BRASIL, 2016).

O atual modelo Tecnocrático e hegemônico de atenção obstétrica e neonatal, onde o processo do parto e do nascimento frequentemente é percebido como um processo patológico. E apesar de a OMS afirmar que o parto é um evento natural que não necessita de controle, mas sim de cuidados, o modelo de atenção ao parto 'normal', mais comum no Brasil, inclusive em hospitais de ensino, é centrado no profissional médico em instituição de saúde hospitalar, razão pela qual é também chamado de parto normal hospitalar (BRASIL, 2014).

Esse sistema é marcado por intervenções obstétricas desnecessárias, e muitas mulheres relatam que o parto é experiência dolorosa, permeada de ofensas, humilhação e expressão de preconceitos à sexualidade da mulher. Essa realidade é cotidiana e cruel e revela uma grave violação dos direitos humanos e direitos das mulheres. Justificando o movimento pela humanização do parto e do nascimento, e a retomada do protagonista da mulher no parto, com seu empoderamento em relação ao seu corpo, à gestação, às mudanças esperadas e possíveis, além de tudo que envolverá o processo do nascimento (ZANARDO et al., 2017).

Para evitar diversos tipos de violência pelas quais as gestantes e parturientes passam, que envolvem ofensa verbal e física, foi sancionada em janeiro de 2018, pelo governo de Santa Catarina, a lei 17.097 contra a violência obstétrica, projeto de autoria da ex-deputada Ângela Albino. A lei obriga a implantação de medidas de informação e proteção à gestante e parturiente, com exposição de cartazes sobre o tema em hospitais, unidades de saúde e demais locais de atendimento à gestante. $\mathrm{O}$ objetivo é conscientizar as gestantes para que conheçam seus direitos (SANTA CATARINA, 2017).

É notável que, mesmo existindo tentativas de mudanças com base em leis e portarias, visando a qualidade e humanização da assistência obstétrica, para que aconteça uma real mudança na assistência ao parto, é imprescindível haver transformações no paradigma que sustenta as práticas, as rotinas hospitalares, práticas dos profissionais de saúde e a própria formação médica (SANTOS et al., 2016).

Essas mudanças amparadas por lei e recomendações enfatizam o cuidado prestado às mulheres, incluindo o resgate do parto natural. Isso também têm estimulado a qualificação das equipes de saúde na assistência à gestação e ao parto, além de ações de incentivo para que o parto seja tratado como um processo fisiológico, conduzido a partir da perspectiva da humanização (POSSATI, et al., 2017). 
Tipos de parto protagonizados na atualidade

No final da gestação, um dilema se coloca quanto à escolha do tipo de parto: oportunidade não ofertadas para todas as mulheres, visto que, as que usufruem das instituições privadas, podem optar dentro das possibilidades da gestação entre a cesárea e o parto vaginal. Todavia, para outras, o dilema está em justamente em não poder escolher (VENDRÚSCULO et al., 2015).

A cesárea e o parto normal são as optativas que existem para a mulher escolher havendo variações nas formas de realizar o parto normal, assim, é direito da gestante a escolha do parto que deseja realizar, analisando os riscos e benefícios de cada um. Desta forma, dar à mulher a oportunidade de participar das decisões em relação ao que lhe foi informado interpõe uma obrigação ética e legal dos profissionais de saúde, oferecendo informações claras e completas a respeito do cuidado, dos tratamentos e das alternativas (NASCIMENTO et al., 2015).

Os profissionais de saúde devem informar à mulher de forma clara e completa acerca do cuidado, do tratamento e das alternativas de parto disponíveis desde o pré-natal. O parto normal é ativo e mais saudável por ser uma forma natural, colocando a parturiente como protagonista no ato, isto não é sentido no parto cesáreo, pois a mulher assume a postura passiva, perdendo em partes o sentido do protagonismo. Algumas mulheres que desejavam o parto normal, porém, passaram pelo procedimento de cesárea, revelaram sentimento de frustração, perda do controle e do protagonismo, por não alcançar o objetivo de realizar o parto normal (NASCIMENTO et al., 2015).

Há um questionamento crescente entre obstetras, enfermeiras, mulheres, doulas fisioterapeutas e entre as próprias mulheres sobre a melhor posição de parir. A polêmica é deixar as posições horizontais tradicionais e adotar as posições verticais, seja ajoelhada, sentada, em pé ou acocorada (BALASKAS, 2008). Sabendo que as posições verticais são mais favoráveis para aceleração do trabalho de parto e mais fisiológicas para parir (LAWRENCE et al., 2011), além de facilitarem a dequitação da placenta espontaneamente evitando assim o manejo ativo através de trações (BALASKAS, 2008). A mulher deve ter liberdade de escolha para determinar o sucesso do seu parto e a qualidade da experiência, tanto para ela, quanto para o bebê (BALASKAS, 2008; WEl et al., 2011).

\section{Parto Cesáreo}

A Cesárea é uma intervenção cirúrgica particularmente concebida para diminuir as ameaças de complicações maternas, assim como também fetais durante a gravidez e o trabalho de parto. A OMS recomenda que a quantidade de partos por cesariana em relação ao número total de partos praticados em um serviço de saúde seja de 15\%, uma vez que devem ter indicação precisa. O Brasil possui uma das taxas de cesárea mais exorbitante do mundo e tem sido apontado como exemplo do abuso desse procedimento (INAGAKI et al., 2014). O percentual atual gira em torno de 55,5\% (SANTA CATARINA, 2017).

O desejo da mulher por uma cesariana é amparado pelo medo, pela conveniência e pela desinformação. Em sua maioria, a gestante teme as consequências do parto vaginal por considerá-lo uma experiência arriscada. A mulher tem a ideia ilógica de que o ato cirúrgico proporciona diminuição da dor. 
Além da desinformação, as práticas desnecessárias durante o trabalho de parto e as violências obstétricas transformam o que seria um acontecimento normal em um procedimento insensibilizado, elevando ainda mais as sensações dolorosas e os medos, o que contribui para a aceitação e solicitação da cesariana. O medo da dor vivenciada no parto normal também é um como fator contribuinte e relevante para a escolha da cesárea (NASCIMENTO et al., 2015).

As indicações mais corriqueiras de cesariana são: falha na indução, feto não reativo, apresentação pélvica, cesárea prévia, desproporção cefalopélvica, descolamento prematuro de placenta, gestação gemelar, placenta prévia, situação transversa, entre outras. Todavia, sabe-se que a morbidade materna ocorre com maior frequência e de forma mais grave em cesarianas, além do mais apresenta riscos relacionados à anestesia, infecção puerperal com sepse e episódios tromboembólicos, mulheres que tiveram uma cesárea prévia dispõem de maior risco de ruptura uterina, placenta prévia, placenta acarreta, descolamento prematuro de placenta e gestação ectópica. Sob outra perspectiva, a cesárea demonstra menor risco de incontinência urinária quando comparada ao parto normal (REIS et al., 2009).

Segundo Mandarino et al. (2009), as cesáreas envolvem aumento da morbimortalidade materna e neonatal, sobressaindo-se a infecção puerperal e a prematuridade agregado com um retardo na recuperação puerperal, maior tempo de internação, maior tempo de assistência por profissionais de saúde, maior uso de medicamentos, início tardio da amamentação, ocasionando elevação de gastos para o sistema de saúde.

A cesárea eletiva, para Vicente et al. $(2017$,$) estão associadas a maiores riscos para a saúde materna$ e infantil, para a parturiente ampliam os riscos de intercorrências como hemorragias, infecções puerperais, embolia pulmonar, complicações anestésicas e morte materna. Já para o recém-nascido ocorre mais chances de serem acometidos por problemas respiratórios, icterícia fisiológica, prematuridade iatrogênica, anóxia e mortalidade neonatal entre outras.

\section{Parto Normal}

O parto normal é aquele que transcorre espontaneamente como um acontecimento natural, sendo assim, considerado também como parto natural. Para que este evento seja classificado como parto normal, precisa ser desempenhado sem a interferência de intercorrências ou procedimentos desnecessários ao longo do trabalho de parto propriamente dito, bem como no parto e pós-parto, assegurando a prestação de atenção frequente para garantia dos direitos, tanto da parturiente, quanto do recém-nascido, visando o bemestar de ambos os envolvidos (FERREIRA et al., 2014).

As complicações próprias do parto normal são menos graves quando comparadas com aquelas advindas do parto cirúrgico. A amamentação do recém-nascido se torna mais fácil e mais saudável a ele; a infecção hospitalar é muito menos frequente no parto normal. Por outro lado, esse produz, pela espera, ansiedade na futura mãe. Essa ansiedade é aumentada também pela preocupação com as dores do parto (VICENTE et al., 2017).

O estudo de Velho et al., em 2012, mostraram que mulheres que preferem o parto normal relatam como benefícios pouco sofrimento, recuperação mais rápida, requerer menores cuidados, sentir menos dor 
após o parto, a possibilidade de voltar às atividades diárias e ter alta hospitalar mais cedo. Algumas mulheres consideram também que esse tipo de parto não tem desvantagem, sendo valiosa a relação com o bebê, o estar junto com a criança e a emoção do primeiro encontro com o filho. Além do mais, dispor de informações sobre o parto, ter domínio sobre o evento e o grau de relaxamento são percepções positivas a respeito do parto. Outro fator que demanda grande satisfação às mulheres é o contato positivo com a equipe que efetuou a assistência, e a presença de um acompanhante.

\section{Parto a Forceps}

O uso do fórceps obstétrico é realizado buscando encurtar o segundo estágio do trabalho de parto, quando ocorrem indicações maternas ou fetais. Esse dispositivo foi originalmente desenhado com o propósito de realizar partos vaginais em mulheres com fetos mortos ou sem chances de vida, objetivando salvar a vida da mãe. O fórceps, como é apresentado nos dias atuais, foi uma evolução de instrumentos anteriores desenvolvidos pela família Chamberlen no século XVII (CASTRO et al., 2003).

O fórceps também pode ser usado para proteger a mãe portadora de cardiopatias, pneumopatias e tumores cerebrais ou aneurismas. Outra indicação é a presença de cicatriz uterina onde há risco de rotura uterina, buscando evitar a redução do período expulsivo e a exposição da cicatriz ao esforço. As indicações fetais abrangem o sofrimento fetal e a parada de progressão durante o período expulsivo. A constância dessa ocorrência pode indicar óbito fetal ou deixar sequelas irreparáveis.

O sofrimento fetal compreende prolapso de cordão que evoluem com bolsa íntegra até o período expulsivo e apresentações anormais. No prolapso de cordão, tendo condições de praticabilidade e sendo difícil realizar a cesárea, o fórceps pode salvar a vida do feto (CUNHA, 2011). As ações que podem ser exercidas pelo fórceps para finalizar o parto compreendem preensão, rotação e tração. As contraindicações para o parto a fórceps são a falta das condições de praticabilidade e a falta de experiência do obstetra com este procedimento (CUNHA, 2011).

\section{Parto de Cócoras}

O parto de cócoras foi introduzido na cultura ocidental após a observação do processo de parturição em índias. Essa postura aumenta em $28 \%$ a área do plano de saída da pelve de 1,0 a $1,5 \mathrm{~cm}$ os diâmetros do estreito inferior da bacia. A flexão das coxas sobre o abdome também favorece a uma retificação da curvatura lombossacral e rotação superior da sínfise púbica, tendo o mesmo efeito da Manobra de McRoberts sobre a distorcia de ombro, porém, sem os efeitos hemodinâmicos adversos da posição supina (SILVA et al., 2007).

Os exercícios de levantar e abaixar de cócoras é um recurso fisioterápico eficaz para fortalecimento da musculatura perineal e dos membros inferiores durante o pré-natal. Apesar desses benefícios, é uma postura desconfortável para as mulheres, gerando câimbras e dores musculares e dificultando a realização de manobras extrativas ou episiotomia pelo médico, caso estas sejam necessárias (SILVA et al., 2007).

O cócoras é um parto de origem indígena, umas vez que as índias tinham seus filhos de cócoras sendo ajudadas pela ação da gravidade. Nesta forma de parto nem sempre é utilizado a episiotomia, pois acontece 
um favorecimento da musculatura vaginal que se abre para todos os lados as invés de abrir-se para um lado só como acontece no parto tradicional (OLIVEIRA et al., 2006).

A posição de cócoras é essencial nos partos pélvicos, pois diminui o intervalo entre o nascimento do cordão e da cabeça. É a posição mais fisiológica favorecendo a liberdade para movimentação da pelve, melhor angulação para descida do feto e não comprime os grandes vasos abdominais, além de exercer pressão máxima abdominal, reduz trabalho muscular, rela o períneo e otimiza a oxigenação fetal (BALASKAS, 2008).

\section{Parto na Água}

A prática de utilizar a água no decorrer do trabalho de parto e parto é mais antiga do que se imagina. Existem muitos relatos e lendas em diversas civilizações como Grécia antiga, Chipre, algumas tribos africanas, Costa Ocidental da Austrália, Egito Antigo e Guiana. A relato de parto na água ocorreu na França em 1803, quando uma gestante utilizou do banho quente natural para relaxamento e alivio da dor e teve seu bebê pouco tempo depois na água. Na década de 60, Igor Tchaikovsky, um instrutor de natação na União Soviética, ocupou-se a estudar as habilidades do bebê humano no meio aquático.

Percebendo que, quanto menor idade do bebê introduzido na água, maior capacidade de adaptação este possuía, então, Tchaikovsky estimulou a atenção para o parto na água. No Brasil, esse tipo de parto teve início na década de 70, em São Paulo, mas não sendo bem visto, na década de 80 era realizado no Nordeste, no Rio de Janeiro e interior de São Paulo (SCHEIDT, 2014).

O parto na água deve ser adotado por mulheres que se sentem confortáveis e tranquilas na água. A mulher fica dentro de uma piscina ou banheira que possibilita mais liberdade de movimento de sua bacia, isso faz com que a dor do parto seja aliviada e o bebê passe mais facilmente através do canal da bacia. Assim, o parto na água tende a diminuir a dor da mulher e o estresse do bebê. O parto na água faz parte da medicina popular nas mais diversas culturas desde antes do nascimento de Cristo (VENDRÚSCULO et al., 2015).

O parto na água proporciona alguns benefícios como: aumento da satisfação materna com a experiência do nascimento; maior mobilidade da mulher; diminuição da percepção dolorosa; contrações uterinas mais eficientes, o que acelera a dilatação cervical; redução do uso de analgesia; das intervenções no trabalho de parto; da realização de cesariana; e traumas perineais e de experiências traumáticas de parto maior (SCHEIDT et al., 2016), redução dos níveis de adrenalina, o que aumenta a produção de ocitocina endógena; diminuição da compressão da veia cava, aumentando o fluxo sanguíneo para o útero, promovendo contrações uterinas mais eficientes e consequentemente reduzindo o tempo do trabalho de parto (SCHEIDT, 2014; SCHEIDT et al., 2016).

\section{Parto Domiciliar}

O parto no domicílio é uma questão de escolha pessoal, porém, é primordial apresentar recursos e uma infraestrutura adequada, mostrando ser do ponto de vista emocional uma boa opção (OLIVEIRA et al., 2006). O MS lançou, em 2000, o Programa Trabalhando com Parteiras Tradicionais, introduzindo-o entre as 
estratégias para a redução da morbimortalidade materna e neonatal e para a habilitação e humanização da assistência obstétrica e neonatal. Este tipo de parto é considerado um tema polêmico, apesar de haver a liberdade da paciente na escolha do parto e local incluindo nesta modalidade um baixo custo e a satisfação da parturiente. Em países como Canadá, Holanda e Austrália é uma forma legitimada de realização do parto (CUNHA, 2012).

A assistência ao parto e nascimento no Brasil não acontece de forma homogênea. Apesar de a maioria dos partos se realizarem no ambiente hospitalar, o parto e nascimento domiciliar com a presença de parteira tradicional acontecem no país, principalmente nas regiões Norte e Nordeste, acima de tudo em áreas rurais, ribeirinhas, de floresta, de difícil acesso e em populações tradicionais, como quilombolas e indígenas. Entretanto o SUS não considera esta forma de parto e o mesmo não é reconhecido como uma ação de saúde, este ocorre de forma deficiente e em situação de exclusão e isolamento. Não possui respaldo e apoio da rede de atenção integral à saúde da mulher e da criança, muitas parteiras tradicionais não recebem capacitação, não dispõe dos materiais básicos para a assistência e não são remuneradas pelo seu trabalho (CUNHA, 2012).

Existem grandes polêmicas envolvendo o parto domiciliar em função de ser considerado, para a medicina moderna, um ato de retrocesso frente a tantos avanços e recursos de que a saúde conquistou, podendo colocar em risco a saúde da mulher e do recém-nascido. Tal fato demonstra que ainda são pouco compreensíveis, por parte da sociedade, os motivos que levam uma mulher a escolher o ambiente doméstico para realizar seu parto, abrindo mão da tecnologia, da modernidade e da presumida segurança que se encontram nos hospitais ou maternidades (SANFELICE et al., 2015).

\section{Parto Leboyer}

Outra forma de parto vaginal é o Parto Leboyer ou parto sem violência, desenvolvido como filosofia de assistência ao parto pelo médico francês Frédéric Leboyer, em 1974. No Brasil, este movimento iniciou na década de 80, trazido pelo obstétra Cláudio Basbaum, o princípio desse parto é sua maior preocupação com o bebê e a tentativa de reduzir o impacto entre o mundo intrauterino e o extrauterino. Dessa forma, reproduz o ambiente intrauterino, fazendo da sala de parto um ambiente na penumbra, em silêncio, com música suave e após o nascimento contato pele a pele, onde o recém-nascido é colocado em contato corporal com a sua mãe, afim proporcionar aumento do vínculo afetivo entre ambos (VENDRÚSCULO et al., 2015).

\section{Parto Humanizado}

Na década de 80 iniciaram o movimento pelo parto humanizado para retomar a qualidade de assistência à gestante, em contraposição a medicalização e o excesso de aparatos tecnológicos na hospitalização para o parto (CANESIN et al., 2010). Para haver um cuidado humanizado é preciso que a equipe multiprofissional seja capacitada a detectar, sentir e interagir com a paciente e sua família, estabelecendo uma relação de respeito ao ser humano garantindo seus direitos imprescindíveis.

Para ocorrer a sistematização da humanização do parto, existem regras que precisam ser adotadas e incorporadas pelas equipes multiprofissionais. De acordo com o Manual de Humanização, as ações 
promovem ou não a humanização havendo a necessidade de construir uma nova filosofia organizacional implantando uma nova cultura. A estruturação dessa nova cultura envolve a participação do sistema de saúde como um todo e ocorrerá aos poucos, englobando um processo de discussão, elaboração, implementação e análise das ações, campanhas e programas (PRISZKULNIK et al., 2009). Para a realização do parto humanizado, as medidas necessárias não implicam grandes modificações no âmbito da estrutura hospitalar. A mudança de padrões na assistência obstétrica tem sido um obstáculo a ser superado.

Há algumas atitudes a serem tomadas em relação à gestante para promover o parto humanizado. No momento da admissão, propõe-se respeitar a privacidade da mulher e a escolha do acompanhante, e se não houver acompanhante, oferecer a possibilidade de acompanhamento por doulas; durante o trabalho de parto buscar oferecer líquidos via oral para prevenção de episódios de hipoglicemia, disponibilizar suporte emocional, prestar informações sempre que necessário e quando a paciente e ou acompanhantes e familiares solicitarem; e respeitar o direito da mulher à realização ou não da episiotomia, cortar o cordão umbilical somente após a parada da pulsação do cordão. Em relação à posição durante o trabalho de parto, encorajar a posição supina e proporcionar liberdade de deambulação e movimentação (SANTA CATARINA, 2017).

No tocante ao controle da dor existem meios não-farmacológicos não invasivos que utilizam massagens, técnicas de relaxamento, banhos de imersão e muitos outros recursos benéficos. No monitoramento, durante o trabalho de parto acompanhar o bem-estar físico e emocional da parturiente, monitorar o feto por meio de ausculta intervalada. Após a dequitação realizar exame rotineiro da placenta pela inspeção cuidadosa, uso de ocitócicos para prevenir risco de hemorragia, amamentação na primeira hora conforme prontidão do recém-nascido (SANTA CATARINA, 2017).

Acolher, ouvir, orientar e criar vínculo são aspectos fundamentais no cuidado às mulheres, buscando um novo olhar, compreendendo-o como uma experiência verdadeiramente humana. O conceito de humanização engloba atitudes, práticas, condutas e conhecimentos pautados no desenvolvimento saudável dos processos de parto e nascimento, respeitando a individualidade e valorizando as mulheres. Adotou-se o conceito de humanização após a instituição do programa governamental PHPN, com o intuito de qualificar a atenção pré-natal no que refere ao seu acesso e cobertura, mas também aprimorar a atenção aos processos parturitivo e puerperal (POSSATI et al., 2017).

A instituição do PHPN definiu estratégias de melhoria na atenção obstétrica por meio da adoção de medidas que assegurassem o acesso, a cobertura e a qualidade do acompanhamento pré-natal. Além disso, ainda reforçava a necessidade de estabelecimento de vínculos entre a assistência pré-natal e o parto, mudanças na estrutura física dos hospitais e na capacitação dos profissionais, entre outras demandas. Entretanto, apesar dos avanços na letra dos documentos oficiais, observam-se as inúmeras dificuldades encontradas pela proposta na tentativa de promover mudanças no contexto das práticas cotidianas. Há, ainda, altas taxas de morbimortalidade materna e perinatal, dificuldade na operacionalização das mudanças nos fazeres diários, por questões de ordem econômica, social e estrutural, e essas questões se expressam na precária qualidade da assistência prestada (SILVA et al., 2017). 
Humanização no campo da saúde é definida como um padrão baseado em uma abordagem focada na mulher de uma forma ético-estético-política. É ética porque envolve a conduta de usuários, gestores e profissionais de saúde comprometidos e corresponsáveis; é estética porque se atribui ao processo de produção da saúde e de subjetividades autônomas e protagonistas; e é política porque está correlacionada à organização social e institucional das práticas de atenção e gestão na rede do SUS (BARROS et al., 2018).

Desse modo, a definição de atenção humanizada durante o processo de gestação compreende conhecimentos, práticas e atitudes, tendo em vista a garantia do parto e nascimento saudáveis, tendo como objetivo a prevenção da morbimortalidade materna e perinatal. Nessa perspectiva, a humanização do parto é uma situação de respeito à mulher como pessoa única, em questão de cidadania. É o respeito, também, à família em formação e ao bebê, que tem direito a um nascimento sadio e harmonioso (SANTA CATARINA, 2017). As condutas humanizadas envolvem o respeito a gestante, informação, consultar suas vontades e ofertar meios não farmacológicos para alívio da dor como: banho quente, deambulação, massagem, respiração adequada, exercícios na bola, posições verticais, relaxamento (SANTA CATARINA, 2017).

\section{CONCLUSÕES}

A discussão acerca dos tipos de parto refletem a evolução da humanidade e suas relações sociais, e a forma de nascer diz muito sobre os anseios da sociedade e como ela está organizada politicamente. Atualmente, em consequência da violência obstétrica e aumento das taxas de mortalidade materna foram surgindo leis que asseguram o respeito e o cuidado a saúde do binômio mãe-filho, garantindo redução das taxas de mortalidade materna e neonatal e assistencial integral e humanizada a gestantes.

Cabe à mulher escolher o tipo de parto que ela desejar, seja ele parto natural, cesárea, parto na água, parto de cócoras, parto Leboyer ou parto humanizado. E apesar das leis e movimentos feminista e governista em retomar e garantir o protagonismo à mulher no parto, muitas ainda não tem esse direito de escolha $\mathrm{e}$ não são bem assistidas.

\section{REFERÊNCIAS}

ALVES, Â. G.; MARTINS, C. A.; SILVA, F. L.; ALEXANDRE, M. S. A.; CORREA, C. I. N.; TOBIAS, G. C.. Política de humanização da assistência ao parto como base à implementação rede cegonha: revisão integrativa. Revista de Enfermagem da UFPE, Recife, v.11, n.2, p.691-702, 2017. DOI: http://doi.org/10.5205/reuol.10263-91568-1RV.1102201724

BALASKAS, JANET.. Parto Ativo: guia prático para o parto normal. 2 ed. São Paulo: Ground, 2008.

BARROS, T. C. X.; CASTRO, T. M.; RODRIGUES, D. P.; MOREIRA, P. G. S.; SOARES, E. S.; VIANA, A. P. S.. Assistência à Mulher para a Humanização do Parto e Nascimento. Revista de Enfermagem da UFPE, Recife, v.12, n.2, p.554558,2018

BRASIL. Ministério da Saúde. Diretrizes Nacionais de Assistência ao Parto Normal. Brasília: MS, 2017.
BRASIL. Ministério da Saúde. Humanização do parto e do nascimento (Cadernos Humaniza SUS). Brasília: MS, 2014.

BRASIL. Ministério da Saúde. Manual Prático para a Implementação da Rede Cegonha. Brasília: MS, 2011.

BRASIL. Ministério da Saúde. Portaria n.1459 de $\mathbf{2 4}$ de junho de 2011. Institui, no âmbito do Sistema Único de Saúde, a Rede Cegonha. Diário Oficial da União, Brasília; 2011.

BRASIL. Ministério da Saúde. Rede Amamenta Brasil: os primeiros passos (2007-2010). Brasília: MS, 2011.

BRASIL. Portaria n.306 de 28 de março de 2016. Brasília: DOU, 2016.

CANESIN, K. F.; AMARAL, W. N.. Atuação fisioterapêutica para diminuição do tempo do trabalho de parto: revisão de literatura. FEMINA, São Paulo, v.38, n.8, p.329-33, 2010. 
CASTRO, D.; PINHEIRO, C. E.. Utilização do fórceps obstétrico no Brasil e na região Sul. Revista da Associação Médica do Rio Grande do Sul, Porto Alegre, v.47, n.2, p.96-100, 2003.

CUNHA, A. A.. A controvérsia do parto domiciliar. FEMINA, São Paulo, v.40, n.5, p.253-262, 2012.

CUNHA, A. A.. Indicações do parto a fórceps. FEMINA, São Paulo, v.39, n.12, p.549-554, 2011.

FERREIRA, K. M.; VIANA, L. V. M.; MESQUITA, M. A. S. B.. Humanização do parto normal: uma revisão de literatura, Revista Saúde em Foco, Teresina, v.1, n.2, p.134-148, 2014.

INAGAKI, A. D. M.; SILVA, J. C.; SANTOS, M. S.; SANTOS, L. V.; ABUD, A. C. F.; CRUZ, V. C.. Cesárea: prevalência, indicações e desfecho do recém-nascido. Revista de Enfermagem da UFPE, Recife, v.8, n.12, p.4278-4284, 2014.

LAWRENCE, A.; LEWIS L.; HOFMEYR, G. J.; DOWSWELL, T.; STYLES, C.. Maternal positions and mobility during first stage labour. The Cochrane Library, Londres, v.9, n.10, 2013.

LEAL, M. C.; PEREIRA, A. P.; DOMINGUES, R. M.; THEME, M. M.; DIAS, M. A.; NAKAMURA-PEREIRA, M. H. B. B.; GAMA, S. G. N.. Intervenções obstétricas durante o trabalho de parto e parto em mulheres brasileiras de risco habitual. Cadernos de Saúde Pública, v.30, n.1, p.17-47, 2014. DOI: http://doi.org/10.1590/0102-311X00151513

LEISTER, N.; RIESCO, M. L. G.. Assistência ao parto: história oral de mulheres que deram à luz nas décadas de $1940 \mathrm{a}$ 1980. Texto \& Contexto: Enfermagem, Florianópolis, v.22, n.1, p.166-174, 2013

MANDARINO, N. R.; CHEIN, M. B. C.; JUNIOR, F. C. M.; BRITO, L. M. O.; LAMY, Z. C.; NINA, V. J. S.; MOCHEL, E. G.; NETO, J. A. F.. Aspectos relacionados à escolha do tipo de parto: um estudo comparativo entre uma maternidade pública e outra privada em São Luís, Maranhão, Brasil. Cadernos de Saúde Pública, Rio de Janeiro, v.25, n.7, p.1587-1596, 2009.

NASCIMENTO, R. R. P.; ARANTES, S. L.; SOUZA, E. D. C.; CONTRERA, L.; SALES, A. P. A.. Escolha do tipo de parto: fatores relatados por puérperas. Revista Gaúcha de Enfermagem, Porto Alegre, v.36, p.119-126, 2015.

OLIVEIRA, J. C.; SILVA, S. P. C.; RIBEIRO, V. D.; FILIPINI, S. M.; LEITE, F. S.. O conhecimento das gestantes sobre os tipos de parto. In: ENCONTRO LATINO AMERICANO DE INICIAÇÃO CIENTÍFICA E VI ENCONTRO LATINO AMERICANO DE PÓSGRADUAÇÃO, 10. Anais. São José dos Campos: Univap, 2006.

PASCHE, D. F.; VILELA, M. E. A.; MARTINS, C. P..

Humanização da atenção ao parto e nascimento no Brasil: pressuposto para uma nova ética na gestão e no cuidado. Tempus Actas Saúde Coletiva, Brasília, v.4, n.4, 2010.

PASSANHA, A.; BENÍCIO, M. H. D.; VENÂNCIO, S. I.; REIS. M. C. G.. Implantação da Rede Amamenta Brasil e prevalência de aleitamento materno exclusivo. Saúde Pública, v.47, n.6, p.1141-1148, 2013. DOI: http://doi.org/10.1590/S0034$\underline{8910.2013047004807}$

PONTES, M. G. A.; LIMA, G. M. B.; FEITOSA, I. P.; TRIGUEIRO, J. V. S.. Parto nosso de cada dia: um olhar sobre as transformações e perspectivas da assistência. Ciência da
Saúde Nova Esperança, João Pessoa, v.12, n.1, p.69-78, 2014.

PORTO, A. A. S; COSTA, L. P.; VELLOSO, N. A.. Humanização da assistência ao parto natural: uma revisão integrativa. Ciência e Tecnologia, Porto Alegre, v.1, n.1, p.12-19,2015.

POSSATI, A. B.; PRATES, L. A.; CREMONESE, L.; SCARTON, J.; ALVES, C. N.; RESSEL, L. B.. Humanização do parto: significado e percepções de enfermeiras. Escola Anna Nery Revista de Enfermagem, Rio de Janeiro, v.21, n.4, p.1-6, 2017.

PRISZKULNIK, G.; MAIA, A. C.. Parto humanizado: influencias no segmento saúde. $O$ Mundo da Saúde, São Pulo, v.33, n.1, p.80-88, 2009.

REIS, S. L. S.; PENTEADO, C. E. M.; CHATKIN, M. N.; ESTRELA, M. S.; PORTO, P. G.; MUNARETTO, M. M.. Parto normal X parto cesáreo: análise epidemiológica em duas maternidades no sul do Brasil. Revista da Associação Médica do Rio Grande do Sul, Porto Alegre, v.53, n.1, p.710, 2009.

SANFELICE, C. F. O.; SHIMO, A. K. K.. Parto domiciliar: compreendendo os motivos dessa escolha. Texto \& Contexto - Enfermagem, v.24, n.3, p.875-882.

SANTA CATARINA. Lei n.17097 de 17 de Janeiro de 2017. Dispõe sobre a implantação de medidas de informação e proteção à gestante e parturiente contra a violência obstétrica no estado de Santa Catarina. Florianópolis: DOE, 2017.

SANTANA, F. A.; LAHM, J. V.; SANTOS, R. P.. Fatores que influenciam a gestante na escolha do tipo de parto. Revista da Faculdade de Ciências Médicas de Sorocaba, Sorocaba, v.17, n.3, p.123-127, 2015.

SANTOS, H. F. L.; ARAÚJO, M. M.. Políticas de Humanização o pré-natal e parto: uma revisão de literatura. Revista Científica FacMais, Inhumas, v.6, n.2, p.54-64, 2016.

SCHEIDT, T. R.. Prevalência de partos na água e resultados maternos e neonatais em uma maternidade do setor suplementar de saúde. Monografia (Pós-Graduação em Enfermagem) - Universidade Federal de Santa Catarina, Florianópolis, 2014.

SCHEIDT, T. R.; BRÜGGEMANN, O. M.. Parto na água em uma maternidade do setor suplementar de saúde de Santa Catarina: estudo transversal. Revista Texto \& Contexto: Enfermagem, Florianópolis, v.25, n.82, p.1-9, 2016.

SILVA, L. B. S.; SILVA, M. P. S.; SOARES, P. C. M.; FERREIRA, Q. T. M.. Posições maternas no trabalho de parto e parto. FEMINA, São Paulo, v.35, n.2, 2007.

SILVA, L. N. M.; SILVEIRA A. P. K. F.; MORAIS. F. R. R.. Programa de humanização do parto e nascimento: aspectos institucionais na qualidade da assistência. Revista de Enfermagem da UFPE, Recife, v.11, n.8, p.3290-3294, 2017. DOI: http://doi.org/10.5205/reuol.11135-99435-1ED.1108sup201713

VELHO, M. B.; SANTOS, E. K. A.; BRÜGGEMANN, O. M.; CAMARGO, B. V.. Vivência do parto normal ou cesáreo: 
revisão integrativa sobre a percepção de mulheres. Revista Texto \& Contexto, v. 21, n. 2, p. 458-466, 2012.

VENDRÚSCOLO, C. T.; KRUEL, C. S.. A história do parto: do domicílio ao hospital; das parteiras ao médico; de sujeito a objeto. Disciplinarum Scientia, Santa Maria, v.16, n.1, p.95107, 2015.

VICENTE, A. C.; LIMA, A. K. B.; LIMA, C. B.. Parto cesáreo e parto normal: uma abordagem acerca de riscos e benefícios. Revista Temas em Saúde, João Pessoa, v.17, n.4, p.24-35, 2017.
WEI, C. Y.; GUALDA, D. M. R.; SANTOS JUNIOR, H. P. O.. Movimentação e dieta durante o trabalho de parto: a percepção de um grupo de puérperas. Revista Texto \& Contexto: Enfermagem, Florianópolis, v.20, n. 4, p. 717-25, 2011.

ZANARDO, G. L. P.; CALDERÓN, M., NADAL, A. H. R.; HABIGZANG, L. F.. Violência obstétrica no Brasil: uma revisão narrativa. Psicologia \& Sociedade, Belo Horizonte, p.1-11, 2017. DOI: http://doi.org/10.1590/18070310/2017v29155043

A CBPC - Companhia Brasileira de Produção Científica (CNPJ: 11.221.422/0001-03) detém os direitos materiais desta publicação. Os direitos referem-se à publicação do trabalho em qualquer parte do mundo, incluindo os direitos às renovações, expansões e disseminações da contribuição, bem como outros direitos subsidiários. Todos os trabalhos publicados eletronicamente poderão posteriormente ser publicados em coletâneas impressas sob coordenação da Sustenere Publishing, da Companhia Brasileira de Produção Científica e seus parceiros autorizados. Os (as) autores (as) preservam os direitos autorais, mas não têm permissão para a publicação da contribuição em outro meio, impresso ou digital, em português ou em tradução. 